\title{
Management of snake bite victims in a Tertiary Care Intensive Care Unit in North India
}

Sir,

We read with interest the clinical profile and manifestations of snakebite patients from a Medical College in Rural Area of Himachal Pradesh. ${ }^{[1]}$ We would like to share our experience and emphasize on the different management regimes being followed world over.

Twenty-five cases of snake bite were admitted in our Intensive Care Unit (ICU) from October 2012 to September 2013; three-fourth of them presented from June 2013 to September 2013. Patients with fang marks and swelling, cellulitis, bleeding, and blisters formation at the local site were included; any patient with suspicion of snake bite but no direct evidence was excluded. Mean age was 31.16 years (range: 13-70 years) and male to female ratio was 18:4. All patients presented with neuroparalytic features and reported of snake bite in the night during sleep. The mean duration of the ICU stay was 4.32 days (range: 3-13 days). The mean dose of equine polyvalent antisnake venom (ASV) administered was 48.63 vials (range: $40-60$ vials). No patient had any adverse reactions to the antivenom. No other complication, namely acute renal failure, acute respiratory distress syndrome, cortical venous thrombosis or disseminated intravascular coagulation was reported during hospitalization. They were mechanically ventilated for a mean period of 3.18 days.

Dose of ASV used by Raina et al. [1] was $292.69 \mathrm{ml} \pm 196.27 \mathrm{ml}$ (range: $50-950 \mathrm{ml}$ ) which is 6 times higher than that reported in our series. They have thus reported allergic reactions in $7 \%$ of patients. Test doses have not been shown to have predictive value in predicting anaphylactic reaction or late serum sickness and are not recommended neutralizing power of antivenoms varies from batch to batch and this may be partially responsible for the difference. National Snakebite Management Protocol prepared by Ministry of Health and Family Welfare, India clearly defines the dose and routes of administration of ASV ${ }^{[2]}$ The recommended initial dose of ASV is 8-10 vials administered via intravenous route over a period of $1 \mathrm{~h}$. Repeat doses for hemotoxic species 
is based on the $6 \mathrm{~h}$ rule; maximum recommended dose is 30 vials. Repeat doses for neurotoxic is based on the $1-2 \mathrm{~h}$ rule; maximum dose is 20 vials. Only the lyophilized polyvalent ASV is available in India.

Anticholinesterase drugs have a variable, but potentially useful effect in patients with neurotoxic envenoming. Atropine sulfate $(0.6 \mathrm{mg}$ for adults; $50 \mu \mathrm{g} / \mathrm{kg}$ for children) followed by neostigmine in a dose range of $0.01-0.04 \mathrm{mg} /$ $\mathrm{kg}$ every $1-3 \mathrm{~h}$ up to a maximum of $10 \mathrm{mg} / 24 \mathrm{~h}$ can be administered by intramuscular or intravenous route. Patients are observed over 30-60 min for improved neuromuscular transmission. Neostigmine appears to have no useful role in confirmed presynaptic envenoming, that is poisoning by common kraits and Russell's viper. It is effective in postsynaptic neurotoxins such as those of cobra. ${ }^{[3]}$ "anticholinesterase test" (e.g. "tensilon test") needs to be performed first to check responsiveness of the patient to the drug as is performed for patients with suspected myasthenia gravis. The use of these drugs will help reduce the consumption of ASV, which is generally limited in a developing country like ours. ${ }^{[4]}$ Awareness of the health care providers on this issue needs to be increased and comparative trials need to be done to quantify its dose sparing effect.

Vikas Saini, Dinesh Sardana, Tanvir Samra

Department of Anaesthesia and Intensive Care, Postgraduate Institute of Medical Education and Research, Chandigarh, India

Correspondence:
Dr. Tanvir Samra,
C-II/77 Moti Bagh 1, New Delhi - 110 021, India.
E-mail: drtanvirsamra @ yahoo.co.in

\section{References}

1. Raina S, Raina S, Kaul R, Chander V, Jaryal A. Snakebite profile from a medical college in rural setting in the hills of Himachal Pradesh, India. Indian J Crit Care Med 2014;18:134-8.

2. National Snakebite Management Protocol, India. Directorate General of Health and Family Welfare, Ministry of Health and Family Welfare, India; 2008. Available from: http://www.mohfw.nic.in. [Last accessed on 2014 Jan 30]

3. Watt G, Theakston RD, Hayes CG, Yambao ML, Sangalang R, Ranoa CP, et al. Positive response to edrophonium in patients with neurotoxic envenoming by cobras (Naja naja philippinensis). A placebo-controlled study. N Engl J Med 1986;315:1444-8.

4. Anil A, Singh S, Bhalla A, Sharma N, Agarwal R, Simpson ID. Role of neostigmine and polyvalent antivenom in Indian common krait (Bungarus caeruleus) bite. J Infect Public Health 2010;3:83-7.

\begin{tabular}{|l|l|}
\hline \multicolumn{2}{|c|}{ Access this article online } \\
\hline Quick Response Code: & Website: \\
\hline & www.ijccm.org \\
\cline { 2 - 2 } & Dol: $10.4103 / 0972-5229.138164$ \\
\hline
\end{tabular}

